\title{
LA PARTE DE LOS ÁNGELES: ASCENSO Y FORJA DEL HÉROE COMO RELATO SOCIAL
}

\section{THE ANGELS'SHARE: ASCENT AND FORGE OF HERO AS SOCIAL NARRATIVE}

\author{
Edisa Mondelo González \\ Rubén Sánchez Trigos \\ Alfonso Cuadrado Alvarado \\ Universidad Rey Juan Carlos de Madrid
}

\section{Resumen:}

La parte de los ángeles (Angels'Share, 2012) es uno de los últimos trabajos dirigidos por Ken Loach y en el que el cineasta vuelve a incidir en una de las constantes que vertebran su obra: la hibridación entre un cine de denuncia social, que pone el acento en la situación de las clases más desfavorecidas y/o de aquellos individuos excluidos de un sistema de bienestar en crisis, con estrategias narrativas propias del cine popular de género. En esta ocasión, Loach plantea un relato que, bajo el realismo de su apariencia formal, reproduce los arquetipos y la estructura del viaje del héroe campbelliano, en un guión que hibrida una trama de ascenso $\mathrm{y}$ redención con la búsqueda de un tesoro simbólico.

\begin{abstract}
:
Angels'Share (2012) is one of the last works directed by Ken Loach and in which the filmmaker returns to affect one of the constants that form the backbone of most of his work: hybridization between a cinema of social protest, which emphasizes the situation of the lower classes and / or those people excluded from a welfare system in crisis, with its own narrative strategies of popular genre cinema. However, this time Loach presents a story, which under the realism of its formal appearance, plays the archetypes and the structure of the campbellian hero's journey, in a script that hybridizes a plot of rising and redemption with a symbolic treasure hunt
\end{abstract}

\section{Palabras clave:}

Análisis narrativo; Ken Loach; crisis del estado de bienestar; viaje del héroe; Campbell; realismo social; hibridación genérica

\section{Keywords:}

Narrative analysis; Ken Loach; crisis of the welfare State; hero's journey, Campbell, social realism, hibridization off genres 


\section{Introducción y metodología}

Partiendo de una visión general de la obra de Ken Loach, el objetivo de este artículo es indagar cómo La parte de los ángeles (Loach, 2012) constituye, por un lado, el último ejemplo de esa hibridación entre un cine de denuncia y realismo social y un cine popular de pretensiones más comerciales que recorre gran parte de la filmografía de Ken Loach y, por otro, un desafío a los compartimentos estancos que, aparentemente, suponen estas dos formas de cine. En concreto, se propone la hipótesis de que La parte de los ángeles se sirve de la arquitrama del viaje del héroe, planteada primero por el antropólogo Joseph Campbell y adaptada después a la narrativa por Cristopher Vogler, para desarrollar su discurso: una denuncia de cómo las políticas neoliberales de las últimas décadas, traducidas en la crisis geoeconómica actual, generan una clase netamente marginal de jóvenes excluidos del sistema en la Escocia (en la Europa) contemporánea.

Para ello, el artículo se aproxima primero a estudios que abordan las constantes narrativas y temáticas de la extensa obra cinematográfica de Loach, con especial énfasis, por un lado, en la naturaleza social y de denuncia que vertebra su cine desde sus orígenes en el free cinema inglés y en el campo del documental, y por otro en la hibridación genérica que le ha llevado en no pocos títulos a adoptar estrategias y recursos habituales del llamado cine de género. En una segunda parte más amplia, se propone una lectura de La parte de los ángeles mediante un análisis del discurso que plantea la aplicación del esquema campbelliano y vogleriano del ascenso y la forja del héroe a las peripecias experimentadas por el protagonista del relato, indagando al mismo tiempo en cómo esta arquitrama se pone al servicio de un discurso concreto de orden social y contestatario. Se trata, pues, de confrontar las perspectivas más autorales en el estudio de la obra de Loach con la asunción de modelos narrativos más genéricos.

\section{Loach y el cine del proletariado}

Si existe un director cinematográfico que ha dedicado la mayor parte de su obra a una clase social es sin duda Ken Loach. Aunque el término proletariado nos 
remita a un panorama social pasado donde las ideologías, los manifiestos militantes y la lucha de clases dominaban buena parte de los discursos mediáticos y las obras artísticas comprometidas, Loach pone en el centro de su mirada a una clase proletaria que vive en un escenario radicalmente distinto de aquel que alumbró esta terminología. Loach comienza su trabajo en la mítica década de los sesenta del s. XX. Tras formarse como realizador en la BBC realiza su primera obra que le lanza a la palestra de los documentalistas comprometidos. Cathy come home (1966) trata sobre los problemas de la vivienda en una Inglaterra que empezaba a acusar las fallas del sistema de bienestar forjado tras la Segunda Guerra Mundial. A partir de aquí consolida un conjunto de documentales y filmes en torno a lo que se ha dado en llamar realismo social. Pero ¿̇en qué consiste verdaderamente el realismo social?. Lay, citando a Hallam and Marshment, lo define como "a discursive term used to describe films that aim to show the effects that environmental factors on the development of character trough depictions that emphasise the relationship between location and identity" (Lay, 2002, p. 8).

El cruce entre la situación social y su influencia en la identidad del personaje es fundamental en el núcleo de la obra de Loach. Los personajes de Loach viven en unas décadas donde ven derrumbarse los logros del estado del bienestar conquistados poco a poco tras la Segunda Guerra Mundial. Este proceso alcanza su punto álgido coincidiendo con la etapa de madurez del realizador, con la política neoconservadora británica de los años ochenta y noventa del pasado siglo, que en pos de un nuevo horizonte liberal y a remolque de los nuevos equilibrios industriales y comerciales que trajo la globalización, reestructuró los sectores industriales y de asistencia social que hasta entonces constituían buena parte de los pilares de la sociedad británica. Esta ola de reformas marcó el inicio de un cambio más extenso que se contagió a otros países y que en buena parte explica el por qué los personajes de su cine sirven de modelo de identificación a sus homólogos en el resto de Europa y otros países de economías occidentalizadas.

Las pérdidas que supuso el tatcherismo quedan claramente reflejadas en su último documental, El espíritu del 45 (The Spirit of '45, 2013), en el que expone 
el proceso de construcción del estado del bienestar británico tras la Segunda Guerra Mundial, capitaneado por figuras como el Primer Ministro Clement Attlee, líder laborista que nacionalizó servicios básicos como el agua, el gas o la electricidad y creó el National Health Service como garante de la asistencia médica universal y gratuita. Aquel espíritu construyó un país donde era impensable cuestionar las pensiones de los trabajadores o la asistencia social a una clase que veía como por fin podía vivir dignamente.

Hablamos pues de una clase que toma conciencia de sí misma al reconocerse víctima de los efectos colaterales de los cambios económicos y sociales. Lo interesante de Loach es que muestra este proceso desde una estrategia narrativa $\mathrm{y}$ formal que constituye casi un sello de identidad y permite al espectador aproximarse a cada nuevo filme como si fuera parte de un mosaico más extenso que cobra sentido, no sólo por la obra individual, sino por la intención del conjunto completo.

Si contemplamos la perspectiva que la dilatada y prolífica obra de Loach traza sobre sus personajes y temas, podemos comprobar que su obra es la de un cineasta preocupado por la creación de un fresco sobre ese proletariado británico, y más concretamente sobre los efectos de los cambios globales que las últimas décadas han producido sobre él. Loach diseña ese fresco en torno a varias líneas maestras que se construyen sobre la resolución de un problema fundamental: "Loach is a socialist, and a creative problem that he and his writers have encountered has been the question of how to dramatise issues that they feel strongly about in ways that incorporate a sense that remain attractive to large audiences. (Leigh, 2002, p. 11). Ese interés en llegar al gran público le llevará a desarrollar un estilo a lo largo de su extensa carrera que, sin apartarse de su inicial vocación documentalista, le irá llevando a experimentar con la incorporación de las estructuras de los géneros populares.

Loach elige como motivo central de cada uno de sus filmes un caso concreto, pero dentro de una horizontalidad de personajes y hasta localizaciones que los homogeneiza. Así podemos citar como ejemplo: los problemas de trabajar como albañil sin contrato en Riff-Raff (1991); los efectos de la reestructuración en subcontratas y la externalización en servicios hasta ahora asumidos de forma 
estatal en La cuadrilla (The Navigators, 2001); la desconfianza de los servicios sociales ante el cuidado de los hijos de un matrimonio entre un inmigrante y una británica en Ladybird, Ladybird (1994), o los problemas de identidad nacional diferentes entre la primera generación de inmigrantes y la segunda en Sólo un beso (Ae Fond Kiss..., 2004).

El punto de vista que adopta no es el de un cine militante que busque un manifiesto panfletario vinculado a un determinado partido político. Loach se abstiene de dogmatizar y señalar las tensiones políticas y sociales de un modo didáctico y por el contrario muestra los efectos de éstas en el ámbito privado y personal de los obreros y los inmigrantes. No quiere decir que éstos carezcan de ideología y que no sean capaces de reflexionar sobre su situación y con ellos el espectador, sino que la dramaturgia de los filmes pondrá el acento en sacar a la luz el proceso destructor en el plano individual más que en el colectivo, dando voz, nombre y apellidos a los casos que desde otra perspectiva podrían convertirse en simples sectores que pierden su empleo o bien en masas que se rebelarían contra el sistema. Este proceso de individualización es una estrategia que le permite a Loach, por un lado, humanizar un proceso que visto desde arriba se contempla como una reestructuración despersonalizada y, por otro, lograr una mayor identificación con el espectador.

Fruto de la anterior perspectiva es la asunción de modelos narrativos propios del cine comercial solapados sobre el drama social. Así, en Sólo un beso las diferentes visiones entre dos generaciones de inmigrantes paquistaníes ante cómo y si deben o no mantenerse las costumbres sobre el matrimonio (pactado entre los padres o libre por amor a la manera occidental) lleva a una historia de amor "a lo Romeo y Julieta” entre un joven de origen paquistaní y una chica católica irlandesa. Igualmente Loach recurre con frecuencia a una estructura propia de la comedia dramática, donde los protagonistas son los que llevan el peso de la trama principal con sus connotaciones dramáticas, pero rodeados de personajes que aportan una serie de gags cómicos que rebajan el tono general de la historia. Las tramas giran varias veces en torno a estratagemas más propias de una comedia de enredo que de un filme político, en las que el robo de un bien o alguna pequeña burla se muestran como acciones con más efecto cómico que 
reivindicativo. Incluso filmes con componentes de alto grado dramático como Ladybird Ladybird (1994), donde se narra la lucha de una madre por recuperar la custodia de sus hijos que permanecen tutelados por los servicios sociales, incorporan rasgos propios del melodrama: "Ladybird Ladybird ...It describes the style in which Loach, in what can be described as his mature period, employs genre paradigms as narrative frameworks for his films, integrating these with a developed realist aesthetic" (Leigh, 2002, p. 2). Esta tendencia de hibridación marcará su cine a partir de los años noventa del pasado siglo que inclusive le lleva a proyectar de nuevo su figura como director internacional en filmes como Tierra y Libertad (1995) realizado en España sobre la implicación de un joven comunista británico en la Guerra Civil o La Canción de Carla (1996) sobre la guerrilla nicaragüense. Esta salida de su habitual espacio urbano y de los personajes de la clase trabajadora le lleva a dar un giro a su forma de trabajar y abundar más en la incorporación de estructuras narrativas del cine comercial: "He worked for the first time whit the famous professional actors, hewed more closely to the conventions of melodrama, and, at the one point, adapted himself to genre constrains of the political thriller" (English, 2007, p. 260).

Estos filmes ayudan al reposicionamiento de Loach en la escena internacional, pero no le hacen abjurar de sus orígenes, ni de sus fuentes y planteamientos originales, que retomará en filmes posteriores como el que origina este trabajo, donde vuelve a plantear una dicotomía entre marco social y narración popular.

La fusión entre perspectiva social y modelos narrativos populares lleva a que los personajes se muevan por objetivos que en un principio están lejos del cine social o militante. No quieren crear movimientos de resistencia, ideologizar a sus compañeros o provocar el activismo político. Sus objetivos son los de cualquier familia convencional: casarse y tener un trabajo honrado que les permita mantener a su familia dentro un mínimo nivel de bienestar. Eso no significa que no sean capaces de reaccionar violentamente contra las circunstancias que les oprimen, como en el caso de Riff-Raff donde los obreros queman la obra en la que trabajan como venganza por la muerte de un compañero en accidente laboral. Estas acciones nacen de la motivación 
sentimental más que de la acción militante preconcebida como estrategia revolucionaria.

La cadena cambios sociales-efectos personales nos remite claramente (Mariano Russo, de la Puente, 2007, p. 2) a la influencia del distanciamiento de Brecht. El dramaturgo buscaba en sus obras la historización, ese proceso que muestra las circunstancias personales como producto de un determinado marco social. Este concepto propone "mostrar un acontecimiento o un personaje bajo su luz social, histórica, relativa y transformable. Es revelar los acontecimientos y los hombres bajo su aspecto histórico, efímero, lo cual hace pensar al espectador que su propia realidad es histórica, criticable y transformable, objetivo político que a través de su obra artística persiguen tanto Loach como Brecht" (Mariano Russo y de la Puente, 2007). Así, en la dramaturgia brechtiana, historizar consiste en "rechazar el representar al hombre en su carácter individual y anecdótico, para exponer la infraestructura sociohistórica que sustenta los conflictos individuales. En este sentido, el drama individual del héroe es resituado en su contexto social y político, y todo texto ficcional es histórico y político” (2007). De esta forma el espectador es consciente de los factores que afectan a su vida y de las claves para su cambio. Loach recoge sabiamente esta postura al aunar ese proceso de identificación que mencionábamos más arriba basado en la narrativa popular, la individualización y el motor sentimental con el marco social. Los personajes de Loach no viven su peripecia como una anécdota personal sino como personas individuales pero condicionadas por su entorno, que es casi siempre el detonante de sus acciones. Pasamos así de lo individual a lo colectivo y de lo sentimental a la reflexión analítica.

La otra cara de este proceso es la conclusión final de muchos de los filmes de Loach: ante el movimiento neoliberal que convulsiona las vidas de los obreros, su respuesta personal atomizada se pierde sin que cuajen nuevos movimientos organizados que unan a esta clase social. Loach señala en última instancia el vacío de respuestas innovadoras, de otros modelos que sean capaces de responder a la ola del poder. En medio de esta batalla resisten, como seres solitarios, algunos personajes que intentan convencer a sus compañeros de la falsedad de los argumentos del nuevo orden social: la libre competencia, la 
sociedad del emprendedor, del riesgo, del fin del trabajo para toda la vida, la movilidad laboral, etc. Su oratoria se pierde y quedan como meros recuerdos del pasado.

Narrativamente, Loach deja abiertos muchos filmes y conflictos (como en el caso del final de La Cuadrilla) renunciando a soluciones que puedan estar cerca del final feliz o la solución global a los problemas. El carácter abierto de las tramas redunda en el carácter de puzzle global de los filmes de Loach, que pueden encajarse unos con otros y continuarse a la manera de una serie coral que, bajo diferentes relatos, muestra una misma situación general.

\section{La parte de los ángeles como relato social}

La parte de los ángeles (The Angels' Share, 2012) constituye menos una prolongación que una dulcificación de estas líneas maestras, al atenuar el discurso contestatario social antes apuntado con, por un lado, una estructura propia del relato heroico de aventuras, incluyendo patrones narrativos y arquetípicos identificados en éste, y por otro derivando hacia un registro de tono amable, con puntuales gags cómicos, ya ensayado en anteriores películas del director. Este barniz amable, relativamente optimista, es, de hecho, algo que no ha pasado desapercibido para la mayor parte de la crítica. El crítico Colin MacCabe, por ejemplo, escribía a propósito de su estreno en Cannes: "Loach and his scriptwriter Paul Laverty chose not to make a hardedged drama of the proletariat reclaiming the surplus value that has been stolen from it by a bankrupt capitalist class. Instead we have a charming comedy in which kids on an ineluctable slide to disaster, are suddenly saved by quasi-divine intervention" (2012). El filme, además, cambia la clase proletaria y/o inmigrante habitual de Loach por el retrato de una serie de personajes, residentes en un suburbio industrial de Glasgow, que, por un motivo u otro, se mueven en los límites del sistema.

La película se inicia así con la presentación (casi sin detalle y en algunos casos sólo con voz over y fondo negro, mecanismo que sirve a Loach para contextualizar el entorno en que se va a desarrollar el relato) de diversos personajes ante un tribunal que debe juzgar sus faltas. Tal y como se expone en 
esta secuencia de montaje, todos ellos son exponentes de la crisis de ese sistema de bienestar que se supone es la base de las sociedades occidentales y que, por su propia naturaleza, abandona en sus márgenes a un gran número de individuos a modo de excedentes. Es significativo que todas las faltas que se juzgan a lo largo de estos primeros minutos son de carácter leve (borracheras, orinar en esculturas públicas, robar un pájaro por la simple diversión de hacerlo...). Mediante esta estrategia, Loach parece tratar de apelar a la empatía del espectador para con sus protagonistas, estableciendo de este modo un registro que condicionará el resto del metraje.

No menos significativo resulta que el tribunal encargado de juzgarlos aparezca retratado con un toque paternalista y hasta cierto punto comprensivo con sus faltas. Esto, por un lado, permite a Loach afianzar el registro amable, más cercano al cuento popular que al drama inherente a los hechos que cuenta y, por otro, le sirve para apuntar desde estas primeras escenas la tesis temática que va a vertebrar de forma consistente La parte de los ángeles: la idea del Estado como un ente virtualmente inoperante en estas primeras décadas del siglo XXI, incapaz de gestionar lo que él mismo ha creado, y que, por lo tanto, aboca a aquellos individuos damnificados por esta inoperancia a un individualismo feroz, sin posibilidad de ofrecer una respuesta social cohesionada. Una idea inherente a la filmografía de Loach y que, como Roger Campione ha sabido ver, retrata los efectos del proceso globalizador sobre los poderes estatales de la vieja Europa: la intensificación de la interdependencia global a todos los niveles, afirma Campione, "abre los equilibrios sociales mantenidos hasta hace poco y obliga a superar los viejos esquemas de la autonomía del Estado-nación y la centralidad de la dirección pública nacional para el mantenimiento del Estado de bienestar y, con ello, barre las reivindicaciones históricas y políticas ligadas a tales instancias" (2008, pp. 3-4). Así, en el nuevo mapa mundial trazado por las fuerzas globalizadoras, "las autoridades nacionales pueden, como mucho, encauzar o contener, dentro de ciertos límites, los efectos inadecuados de un proceso globalizador sin control social y político. En cualquier caso, la idea de que sea el Estado, con su dialéctica interna, el principal impulsor de la vida social, política y económica se ha visto abocada al fracaso” (2008, p. 4). 
No es de extrañar entonces que la presencia del Estado en La parte de los ángeles se reduzca, en realidad, a estos primeros minutos (y que lo haga a través de un retrato tan etéreo como el de esos jueces, cuya única herramienta para atajar la situación de estos excluidos sea el de condenarlos a leves penas sociales). Concluida esta secuencia, el relato pasará ya a centrarse en los cuatro protagonistas y en el agente social encargado de sus casos, Harry, obviando cualquier otra forma de intervención estatal, exceptuando el panorama social que el sistema, siempre en off, arroja como resultado de su inacción. Loach parece expresar así su desencanto y su desesperanza con un sistema que a todas luces ha fracasado a la hora de procurar un mínimo bienestar a los suyos. La respuesta, parece sugerir el resto de la película una y otra vez, se encuentra en los propios individuos, en la micro-organización resultante a niveles de barrio, familiares y personales.

Aunque el discurso de Loach a partir de este punto aparenta adoptar una forma colectiva y abarcar la historia de estos cuatro jóvenes condenados a trabajos sociales (por ejemplo, mediante el recurso de filmarlos repetidamente en planos de conjunto de focal larga), pronto pasa a concentrar el arco dramático de la trama en el personaje de Robbie, un joven con un pasado violento relacionado con las drogas al que su reciente paternidad insta a reformarse y al que acompañan en su transformación/maduración tres de los condenados con los que comparte el castigo. Robbie será, pues, el verdadero eje del relato, no sólo porque es el único de estos personajes en cuya historia personal profundiza el guión, sino también porque es el único que experimenta un arco de transformación dramático, siendo éste el que finalmente condiciona y estructura cada una de las fases por las que atraviesa el filme.

En este sentido, La parte de los ángeles resulta, en primera instancia, un relato de redención en un contexto marginal en el que la crisis social y económica parece haber alcanzado proporciones crónicas: como el resto de sus compañeros condenados, Robbie no se encuentra en una situación personal límite como consecuencia específica de un despido, de una crisis laboral sectorial o general o de la merma de sus derechos profesionales, sino que su estatus como figura socialmente excluida parece connatural a su propia existencia, al lugar en que 
ha nacido y que le ha impuesto un modo de vida concreto. Robbie funciona, pues, como un personaje-tipo, representante de una forma muy concreta de joven en la Inglaterra de la crisis actual (o, más ampliamente, de la Europa desarrollada), abocado a la precariedad laboral y social y a la dependencia de los servicios del (como vimos, limitado en sus fuerzas de actuación) Estado británico.

Loach reproduce así, con el retrato que realiza de este personaje, otra de sus señas de identidad habituales: como ya apuntamos, Mariano Russo y de la Puente sugieren utilizar el concepto de "historización” para leer su filmografía. Bajo este proceso, Robbie no es tanto un personaje en sí mismo como un actante que "historiza" el drama y las circunstancias personales de miles de jóvenes en un momento histórico tan concreto como es la presente crisis geo-económica. Resulta significativo entonces que Loach lo filme durante una buena parte del metraje en su entorno social habitual (casi nunca en un espacio anodino que no resulte representativo de su condición), mediante encuadres que permiten contemplar al fondo a otros jóvenes como él en el transcurso de una inacción que se revela cotidiana y crónica: beber, charlar y dejar el tiempo correr en las calles y en los parques. Una existencia que conlleva inevitablemente el coqueteo con las drogas y con la violencia, parece decirnos Loach, quien, como el tribunal de las primeras escenas, evita juzgar a Robbie, disculpándolo a través del retrato humanizado que realiza de él.

Sin embargo, a diferencia de los demás personajes, en cuyas historias personales apenas se profundiza y quienes apenas parecen plantearse metas, Robbie sí emprende un camino de redención a partir del instante en que confluyen el nacimiento de su hijo y la condena a trabajos sociales producto de una pelea eterna con otro joven y su grupo de amigos. Este viaje interior de redención y ascenso (social), narrado a través de peripecias de acción antes que mediante el estudio psicológico del personaje, se articula, como decíamos, mediante un discurso amable a caballo entre el relato popular-costumbrista y el relato de aventuras, y es este matiz el que, finalmente, singulariza La parte de los ángeles en el grueso de la filmografía de Loach. 


\section{Redención, ascenso y forja del héroe en La parte de los ángeles}

Como ya se ha señalado, una buena parte del cine de Loach tiende a solapar modelos próximos a un cine de rasgos más comerciales o populares con otro cine provisto de una perspectiva político-militante que acaba constituyendo, en términos de guión, la propuesta temática de sus filmes. En La parte de los ángeles la plantilla sobre la que parecen trabajar Loach y su guionista Paul Laverty, se mira en los relatos sobre forja del héroe formulados y reformulados una y otra vez por Hollywood desde hace décadas. Una arquitrama universal que, como señala Sánchez-Escalonilla (2002), bebe de las fuentes míticas y literarias de tantos héroes y de cuya efectividad dramática da cuenta el incansable uso que hacen de ella tanto los guionistas del pasado como los contemporáneos.

Así, no es difícil detectar en el guión de la película los doce pasos del héroe descritos por el antropólogo Joseph Campbell en su muy influyente ensayo El héroe de las mil caras, repasados después por Cristopher Vogler y que aquí aparecen convenientemente adaptados a las constantes de Loach antes apuntadas. De este modo, y siempre según Campbell, los héroes de los relatos míticos: 1) Son presentados en el mundo ordinario, donde 2) reciben la llamada de la aventura. 3) Dudan al comienzo o rechazan la llamada, pero 4) son animados por un mentor para 5) cruzar el primer umbral y penetrar en el Mundo Especial, donde 6) encuentran pruebas, aliados y enemigos. 7) Se encaminan hacia la gruta abisal, cruzan el segundo umbral, 8) donde afrontan la prueba suprema. 9) Se apoderan de su recompensa y 10) son perseguidos en el camino del regreso hacia el mundo ordinario y 11) quedan transformados tras la experiencia. 12) Regresan con el elixir, beneficio o tesoro vital para el Mundo ordinario (2002, p. 30).

En La parte de los ángeles, Robbie es presentado inicialmente como alguien confinado, a su pesar, en ese suburbio que constituye su mundo ordinario, responsable en gran parte de su pasado delictivo y empeñado en ahogar cualquier posibilidad de redención. Esta situación encuentra una posible salida cuando recibe la ayuda de Harry, el agente social que le ha sido asignado, quien 
le acoge y le protege, y quien, sobre todo, le revela un don cuya existencia el propio Robbie desconocía: una facultad natural, pero al mismo tiempo extraordinaria en alguien de su posición, para la cata de whiskys, por encima incluso de catadores experimentados y profesionales. La película narra así la irrupción de un elemento extraordinario (casi de origen divino, rozando la verosimilitud, pues Robbie nunca antes había tenido contacto con el mundo del whisky) en la vida de un personaje aparentemente condenado a la marginalidad, elemento que constituye una forma de llamada a la aventura, a lo desconocido: en primer lugar, propicia un recorrido por destilerías y catas que llevará a Robbie y a sus compañeros a un mundo social y geográficamente alejado del suyo, y en segundo y último lugar a la proyección y la ejecución de un robo (un whisky único que cumple la función de tesoro simbólico), última prueba que permitirá a Robbie acceder a su objetivo: la consecución de una vida mejor con su pareja y su hijo recién nacido. En este sentido, no es casual que el guión haga coincidir el nacimiento del bebé y la primera cata de whisky por parte de Robbie, homologando así la motivación y la herramienta para alcanzarla.

En este proceso de redención, Harry cumplirá un papel decisivo. Harry encarna el papel de un mentor de rasgos paternales, que anima a Robbie a salir de su mundo (psicológica y literalmente) y adentrarse en otro ignoto, tan lleno de peligros como de recompensas. De acuerdo con Vogler, la figura del mentor tiene como funciones tanto enseñar algo al héroe (por ejemplo, algún tipo de destreza que necesita ser ejercitada), como animarle a adentrarse fuera de su entorno (otorgarle confianza) como, finalmente, proporcionarle algún don (que no necesariamente debe ser tangible, puede tratarse simplemente de un consejo que el héroe pueda emplear en un momento crucial de su aventura) (2002, pp. 77-78). No es de extrañar que en su análisis de los cuentos rusos, Vladimir Propp llame a esta figura el donante o dador, potenciando esta función por encima de otras.

En La parte de los ángeles, es Harry quien traslada a Robbie y sus compañeros fuera de sus límites habituales, mediante los viajes en furgoneta que terminan descubriendo el universo de las catas de whisky. Al mismo tiempo, el propio Harry es alguien con cierta experiencia, un catador aficionado que identifica en 
el joven al que acaba de conocer a un extraordinario e insospechado catador. Harry, como corresponde a su estatus de mentor, iniciará entonces un proceso de entrenamiento que llevará a Robbie a ascender en el mundo de las catas al tiempo que le proporciona un salvoconducto viable con el que escapar de la marginalidad que lo acecha; pero, sobre todo, Harry será decisivo a la hora de afianzar la confianza de Robbie, tras una primera negativa de éste a emprender este camino simbólico. Así, tras la primera visita a una destilería, Harry lleva a Robbie a Edimburgo para involucrarlo en una cata con un gran Maestro. Esa cata demuestra públicamente el potencial de Robbie y le permite conocer a un interesante contacto, perteneciente a otra clase social y a otro mundo al que ellos no tienen acceso, que será determinante en la resolución de la trama, es decir, en la victoria de Robbie.

La relación Harry-Robbie es determinante en la decisión de Robbie de emprender una nueva vida, motivación que guía cada uno de sus pasos a lo largo de la película. La escena en la que Robbie demuestra su potencial ante un gran Maestro aparece configurada como la primera gran prueba que el protagonista debe superar, a partir de la cual el paso del primer umbral se hará efectivo (el ingreso de Robbie en el mundo de las catas de whisky). Como Campbell advierte, "esta es la fase favorita de la aventura mítica”, la que "ha producido una literatura mundial de pruebas y experiencias milagrosas”. A partir de este instante, "el héroe es solapadamente ayudado por el consejo, los amuletos y los agentes secretos del ayudante sobrenatural que encontró antes de su entrada a esta región" (1959, p. 94).

Además de la figura del mentor, Campbell y Vogler hablan también de aliados y de enemigos, cuyas funciones opuestas (ayudar y retrasar la consecución del objetivo por parte del héroe, respectivamente) configuran, en definitiva, el mapa de las peripecias del protagonista. Así, en realidad es Mo, compañera de Robbie en la pena de trabajo social, quien le proporciona el definitivo acceso a la prueba final. Mo es una ladronzuela con mala suerte que roba simplemente aquello que es fácil, ni caro ni necesario, aquello que se pone al alcance de su mano. En este caso, Mo contribuye al entrenamiento de Robbie al robar en la destilería una colección de botellitas de distintos whiskys que permitirán a éste practicar sus 
conocimientos. Al mismo tiempo, son las ligeras manos de Mo las que proporcionan a Robbie el detonante que le pondrá sobre la pista de la prueba final, al robar unos documentos del Gran Maestro catador en los que aparece la información sobre la localización y la fecha de la subasta de un Malt Mill, el Santo Grial de los whiskys. Dichos documentos cumplirán la función de mapa del tesoro (función que, visualmente, se afianza con el color dorado del cotizado líquido).

Los restantes compañeros en la pena por servicios sociales completan el grupo de aliados con los que Robbie contará en su asalto final a la destilería (con funciones de castillo) donde se guarda el Mat Mill. Resulta significativo en este sentido que todos ellos se agrupen en torno a la figura de Harry en tanto maestro-padre, reforzándose así la idea de grupo.

Una vez más, las constantes autorales de Loach y la estructura narrativa del relato heroico de aventuras aparecen conciliadas, en un nuevo ejemplo de esa práctica habitual en el director británico que consiste en servirse de herramientas del cine más popular para articular su discurso temático. En el caso de La parte de los ángeles, los aliados de Robbie en su aventura cumplen la función de asumir la totalidad de los gags de la película. Son ellos quienes protagonizan todas las escenas de registro cómico, lo que permite a Loach concentrar el peso dramático en el viaje interior de Robbie y en su relación maestro-discípulo con Harry. Así, después de que hayan completado el robo final y hayan huido con el cargamento, el personaje de Albert protagoniza el último de los grandes gags de la película cuando, accidentalmente, rompe una de las botellas, derramando el whisky de la misma. Esto, por un lado, ayuda a profundizar en la distinción social entre los dos mundos retratados en el filme (la imagen de un individuo marginado socialmente echando a perder un bien tan preciado por las clases superiores resulta icónica y poderosa, lo mismo que el hecho de que porten el whisky en botellas de refresco, paradoja que en sí misma resume el espíritu del relato). Por otro lado, proporciona a Robbie la oportunidad de afrontar una última prueba que certifique el cambio operado en él: gracias a este accidente, Robbie tomará la decisión de presionar al comprador del whisky robado, en una escena que visualiza claramente la 
distancia que separa al Robbie del inicio del filme del Robbie astuto y seguro de sí mismo que es ahora. Podría decirse que, aunque su desliz reviste aparentemente un registro cómico, la función de Albert sigue siendo la de un ayudante que con sus acciones ayuda al héroe a completar su viaje. El hecho de que dichas acciones tengan un carácter inconsciente no hace sino singularizar más la relación que La parte de los ángeles mantiene con la arquitrama campbelliana/vogleriana que nos ocupa.

En el lado opuesto, el retrato de los enemigos que van a interponerse entre Robbie y su objetivo sirve a Loach, en primer lugar, para ofrecer el contapunto dramático a los gags cómicos protagonizados por sus ayudantes, y en segundo lugar, le ayuda a profundizar en el proceso de "historización" mediante el cual La parte de los ángeles traza un fresco, en el fondo más amargo de lo que su registro deja entrever, de los ambientes suburbiales británicos en el presente periodo de crisis. Son tres los principales escollos con los que Robbie va a toparse en su aventura hacia una nueva clase social: en primer lugar, el constante acoso al que Clancy y sus amigos le someten, que llega hasta el punto de amenazar la vida de su bebé. Las "escenas eliminadas” que se incorporan como extras en el DVD del filme desarrollan de hecho esta subtrama, determinante en la vida de Robbie, mostrando a Clancy y los suyos acosando a Robbie en un par de escenas no incluidas en el montaje final. En segundo lugar, la oposición del padre de Leonie a la relación de pareja que mantienen ambos jóvenes y en la que llega incluso a propinar a Robbie una paliza y luego a ofrecerle dinero para separarle de su hija. La relación con Leonie (que se ajusta claramente a un arquetipo narrativo materno, con él, reprochándole su comportamiento y siendo la voz de su conciencia, y con su hijo, al que protege frente a todo) es fundamental para Robbie ya que constituye un horizonte aspiracional que forma parte capital de sus motivaciones para emprender su aventura. En tercer y último lugar, y probablemente más determinante, está el propio pasado de Robbie. En este sentido, Loach nos cuenta, aunque no nos muestra, cómo sus padres entraban y salían de la cárcel constantemente, y cómo la huella de este estigma (el entorno social del que Robbie no parece poder disociarse) justifica en gran parte sus ataques de ira y violencia, razón por la que anteriormente él también ha estado en la cárcel (cuando cometió una agresión 
bajo los efectos de la cocaína contra un joven). De hecho, los tres enemigos de Robbie pueden homologarse como uno sólo: el estigma connatural a un joven nacido y crecido en los suburbios industriales de la Escocia actual.

En esta dirección ahonda también el hecho de que Harry adopte las características de una figura paternal en su relación con Robbie, ya que, como Vogler apunta, “el arquetipo del mentor está estrechamente relacionado con la imagen del padre (...) Muchos héroes buscan mentores porque sus propios padres no son modelos adecuados" (2002, p. 52). El principal enemigo de Robbie es, pues, el propio Robbie, o mejor dicho: el Robbie del pasado que intenta dejar atrás en el instante en que toma la decisión de emprender una nueva existencia junto a Leonie y su hijo. Una constante narrativa de las tramas de redención y purificación (véase Balló y Pérez, 1997), a las que La parte de los ángeles parece apelar en cada escena. El objetivo de Robbie como héroe entonces es triple: abandonar las actividades que le han llevado al punto en el que le encontramos, emprender un nuevo camino vital con su recién formada familia y reconciliarse consigo mismo mediante la purificación de todo lo hecho en el pasado.

Presentados y caracterizados los personajes que van a acompañar a Robbie en su forja, la película avanza hacia los estadios restantes del viaje heroico: Robbie y los suyos (Harry permanece al margen durante esta parte del metraje) cruzan el segundo umbral (una cata de whiskys que se diría definitiva por las propiedades exclusivas del whisky que se va a subastar allí) y se encaminan hacia la gruta abisal (una importante destilería) en donde se proponen llevar a cabo el robo que podría apartarles definitivamente de su existencia marginal: la sustracción de una parte del Malt Mill la noche antes de que tenga lugar su subasta ante un auditorio de selectos potenciales compradores.

De nuevo, la película concilia las herramientas narrativas y dramáticas del relato popular heroico ya que, tanto el guión como la puesta en escena de Loach, se esfuerzan en subrayar el carácter definitivo del robo perpetrado por Robbie y sus amigos, el carácter crucial de una prueba que supone el estadio final del viaje de los personajes. Por un lado, tenemos la forma en que se configura la destilería: como un espacio de exclusivo acceso que encierra a su vez otro 
subespacio (la bodega con los whiskys) al que todavía resulta más difícil acceder. La destilería cumple entonces las funciones de esa gruta abisal descrita por Vogler, a la que el héroe debe precipitarse en una suerte de descenso hacia su propia psique para obtener ese objeto extraordinario que ha ido a buscar. En palabras de Campbell: "el castillo dormido es el último abismo en el cual la conciencia se sumerge al descender en el sueño" (1959: 160). Por otro lado, las escenas del robo guardan ecos del género de espías, incluyendo las fases Preparación del robo-Ejecución del robo-Complicación del robo-Huida con el botín. No es casualidad que sea Robbie el encargado de liderar tal empresa, ni de que sean sus manos las que transportan el botín hasta el exterior de la destilería. La prueba final del grupo es, al fin y al cabo, la prueba final de Robbie, quien, al contrario que sus amigos (mucho más interesados en las perspectivas lúdicas de la hazaña), ha puesto en esa recompensa extraordinaria en forma de whisky las esperanzas de un futuro ascenso social.

Tras el robo, el guión de Paul Laverty elimina prácticamente la persecución de los protagonistas en su regreso al mundo ordinario (o al menos atenúa considerablemente la sensación de amenaza) para centrarse en el paso 11, es decir, en la transformación que se ha operado en el héroe tras el viaje y la consecución de su objetivo. Como ya se señaló, la rotura de una botella por parte de Albert hace que Robbie cambie las reglas en la negociación con el comprador del whisky robado. Esta escena y aquella en la que Robbie se marcha junto a Leonie y su hijo para vivir la vida que se ha ganado, funcionan como ejemplarización de este nuevo Robbie que nos es presentado al final del relato. Véase, a este respecto, la escena en la que Harry recibe también su propia botella de whisky como muestra de gratitud por parte de su discípulo, y que sugiere la idea de un Robbie reconciliado consigo mismo y con los agentes que han propiciado su ascenso. Dicho ascenso, sin embargo, contraviene un aspecto esencial del relato campbelliano, pues, como se verá en el siguiente epígrafe, la consecución del objeto extraordinario no se da en beneficio del mundo ordinario del cual procede el personaje, sino que reviste un individualismo feroz. Desengañado del sistema, Robbie sólo roba para ayudarse a sí mismo y a su familia. 


\section{La subversión como respuesta social}

La narrativa mítica del héroe se encuentra, de este modo, re-codificada y condicionada en La parte de los ángeles por el discurso crítico-social habitual de Loach, deviniendo en una mera plantilla-guía que se limita a subrayar los diferentes estadios por los que atraviesa Robbie hasta alcanzar su maduración y su objetivo. Usando como mecanismo narrativo el arco dramático que transforma a Robbie de vulgar delincuente menor en padre de familia responsable, la tesis que arroja la película ahonda en el profundo desencanto que Loach parece sentir por las instituciones estatales británicas y que apuntábamos al inicio de este análisis: en su película, el Estado no puede proporcionar soluciones ni respuestas al individuo común, que se encuentra condicionado por una determinación clasista que la crisis no hace sino afianzar. Dichas respuestas deben venir (y vienen) de los propios individuos, organizados entre ellos o en comunidades menores para su propia supervivencia. Como Mariano Russo y de la Puente apuntan, Loach "recupera desde un medio masivo como el cine la dimensión conflictiva de lo popular, y lo hace al mostrar pequeñas victorias de los actores populares en la vida cotidiana, y las tácticas en el nivel micro de las prácticas de resistencia" (2007). Es significativo a este respecto que Harry decida saltarse cualquier vía administrativa-oficial (bordeando incluso la legalidad) a la hora de ayudar a Robbie y sus amigos: si las tareas de servicio social a las que han sido condenados se revelan a todas luces ineficaces, la aventura que supone el introducir a los chicos en el mundo de la cata de whiskys obtiene, en cambio, un resultado positivo: al final de la misma, Robbie ha encontrado una vía con que superar la situación de exclusión social en la que se encontraba al inicio de la película.

Por otra parte, el proceso de humanización mediante el cual Loach retrata positivamente a unos personajes que en cualquier otro relato podrían hacer las funciones de delincuentes apunta también en esta dirección: así se subraya que el plan urdido por Robbie y los suyos no contempla robar todo el whisky, sino solo una pequeña parte ("la parte de los ángeles", ese $2 \%$ que se pierde por evaporación durante el proceso de envejecimiento en la barrica), algo que no 
perjudicará a nadie, que nadie notará y que a ellos les permitirá cambiar por completo su vida y alcanzar esos objetivos a los que aspiran. Robbie no pretende realizar el robo del siglo ni convertirse en millonario; sus únicas aspiraciones son alcanzar un pequeño estatus de clase media tradicional: tener una familia y un trabajo y una casa que le permitan cuidar de ellos, objetivo susceptible de ganarse la simpatía del espectador.

Esta perspectiva incluye incluso al propio Harry. Como revelan las "escenas eliminadas" del montaje final, Harry es, como los jóvenes a los que debe guiar, otro tipo de perdedor, cuya caída en desgracia en este caso si se encuentra claramente vinculada a la crisis económica. Como le acaba confesando a Robbie en una de esas escenas, en un pasado reciente Harry era un próspero empresario que terminó por perder su negocio al ser incapaz de cobrar la gran cantidad de dinero que le adeudaban sus acreedores. La pérdida económica acabó suponiendo también una pérdida personal cuando esta situación provocó que su mujer se divorciase de él. Su bonhomía y sus propias circunstancias personales hacen que Harry empatice con los personajes de los que es responsable y se entregue a ellos más allá de lo que su trabajo le exige, llegando casi a transgredir la ley cuando les lleva a la destilería utilizando la furgoneta oficial en un día no laboral. La historia personal de Harry es, pues, otra forma de "historización", ya que le convierte en otro personaje-tipo, ejemplarizante de todos esos empresarios que han perdido su negocio en los últimos años, precisamente por no adoptar las maneras feroces que el estado capitalista parece exigirles.

\section{Conclusiones}

Bajo un registro amable, puntualmente cómico, La parte de los ángeles encierra una tesis tan amarga como subversiva: el sistema no funciona, y sólo la acción individual de cada uno puede dar algún resultado, siempre en beneficio propio o de quienes nos rodean más íntimamente, pero nunca como parte de una estrategia revolucionaria colectiva. En otras palabras, en La parte de los ángeles los personajes actúan movidos por un individualismo emocional, casi se diría que motivado por la supervivencia, antes que por un sentimiento puramente 
político que, aunque pudiera latir subrepticiamente, en última instancia parece destinado a fracasar como movimiento colectivo. En este sentido, no existe en el personaje del héroe protagonista un compromiso social que dirija sus acciones y canalice el resentimiento que pudiera sentir hacia el sistema que lo ha excluido.

Por otra parte, no menos significativo resulta el hecho de que, para acceder a ese sistema, el protagonista y sus ayudantes tengan que burlarlo, llegando incluso a transgredir la ley, pues su última prueba no es sino un robo. La película atenúa este aspecto mediante un registro amable-blanco (los personajes son cualquier cosa menos ladrones violentos y profesionalizados, lo que propicia todo tipo de situaciones cómicas durante la ejecución de esta operación) que aporta, además, un último apunte crítico-social propio de su director: la respuesta a ese neoliberalismo salvaje cuya voracidad subyace detrás del sistema que oprime a las clases medias y bajas sólo puede ser una acción de respuesta por parte de estas, incluso si esta acción se encuentra desintelectualizada. Loach cierra así el círculo, incurriendo en una suerte de justicia poética que parece justificar plenamente las acciones delictivas de sus personajes, mientras que al mismo tiempo endulza la desesperanza que subyace bajo esta ironía: para hacer frente a un sistema en crisis consciente de su propio fracaso, incapaz de proporcionar la menor cobertura a los ciudadanos, el individuo debe burlarlo con las herramientas que tiene a su alcance.

Lo singular del filme es que Ken Loach y su guionista Paul Laverty eligen tratar este tema mediante la aplicación narrativa de una de las arquitramas más populares empleadas por Hollywood durante décadas: el relato de ascenso y forja del héroe. De este modo, La parte de los ángeles se sirve de este esquema para narrar el doble viaje del protagonista: social, ya que persigue salir del ambiente marginal en el que ha crecido, e interior, pues para ello debe purificarse y dejar atrás aquellas acciones delictivas propias de su vida pasada. Su meta es, como la de tantos héroes míticos, construir un hogar en el que poder estar junto a su familia. La clase media se convierte así en un objetivo aspiracional, que conduce al héroe del relato a cruzar las diferentes fases de su forja, la cual acaba adquiriendo las trazas de una trama de ascenso. 
La parte de los ángeles se presenta por un lado, como un ejemplo de hibridación genérica prototípico del cine moderno (la película concilia aspectos de la comedia, el cine de robos y el drama social de denuncia), y por otro supone el encuentro del cine social, deudor del free cinema inglés, propio de Loach con las estructuras más clásicas del relato heroico practicado por la narrativa popular. Este último aspecto difumina las posibles líneas divisorias entre estas dos formas de hacer cine, certificando la universalidad y la funcionalidad del viaje del héroe como herramienta narrativa. Herramienta que en este filme se pone al servicio de una visión muy concreta de la actual crisis económica y social: la del individualismo feroz como única posibilidad de supervivencia, que, paradójicamente, significa revalidar las tesis neoliberales que en principio se cuestionan.

\section{Referencias bibliográficas}

Balló, Jordi \& Pérez, Xavier (1997). La semilla inmortal. Argumentos universales en el cine. Barcelona: Anagrama.

Campbell, Joseph (1959). El héroe de las mil caras. México, D.F: Fondo de Cultura Económica.

Campione, R., (2009). Los derechos flexibles. A propósito de "La cuadrilla" de Ken Loach. ISSL. Italian Society for Law and Literature. http://www.lawandliterature.org/area/documenti/Campione\%20\%20Los\%20derechos\%2oflexibles.pdf

English, J. F. "Local focus, global frame: Ken Loach and the cinema of dispossession" en Friedman, L. (editor) (2007). Fires Were Started: British Cinema and Thatcherism. New York: Columbia University Press.

Lay, S. (2002). British Social Realism: From Documentary to Brit-grit. New York: Columbia University Press.

Leigh, J. (2002). The Cinema of Ken Loach: Art in the Service of the People. New York: Columbia University Press.

MacCabe, Colin. A sentimental education. Film Quarterly Fall 2012, Vol. 66, No. 1 http://www.filmquarterly.org/2013/05/a-sentimental-education/

Mariano Russo, P., de la Puente, M. L. (2007). Ken Loach, el reencuentro con lo popular. Revista Questión, (Vol.: 1, $\mathrm{n}^{\mathrm{0}}$ 15). http://perio.unlp.edu.ar/ojs/index.php/question/article/view/409/33 Z

Martin-Jones, D., (2013). The Angel's Share: Ken Loach and Paul Laverty Lift Scotland's Kilts to Expose Its Darker Parts. Senses of cinema (68). 
http://sensesofcinema.com/2013/feature-articles/the-angels-shareken-loach-and-paul-laverty-lift-scotlands-kilts-to-expose-its-darkerparts/

Matia Portilla, F., Álvarez Rodríguez, I. (2012). El cine en tiempos de crisis. Revista Creatividad y Sociedad ( $\mathrm{n}^{0}$ XVIII). http://www.creatividadysociedad.com/articulos/18/02 el cine en tie mpos_de_crisis.pdf

Propp, V. (1981) Morfología del cuento. Madrid. Ed. Fundamentos

Rodríguez González, C., (2008). El espacio urbano en la "Trilogía de Glasgow" de Ken Loach. Bells: Barcelona English language and literature studies. Vol.: 17.

http://www.raco.cat/index.php/Bells/article/view/141350/192785

Sánchez-Escalonilla, A., (2002). Guión de aventuras y forja del héroe. Barcelona. Ed. Ariel.

Vogler, Cristopher (2002). El viaje del escritor. Madrid: Ma Non Troppo. 